\title{
Chronic purple grape juice consumption induces age- dependent changes on cognitive function in elderly women
}

Pedro Cañete da Costa ${ }^{1}$, Gilson Pires Dorneles ${ }^{2}$, Ivy Reichert Vital da Silva ${ }^{1}$, Cintia Laura Pereira de Araujo ${ }^{2}$, Gustavo Pereira Reinaldo ${ }^{2}$, Alessandra Peres ${ }^{1,3}$, Cláudia Funchal ${ }^{1}$, Pedro Dal Lago ${ }^{2}$, Caroline Dani ${ }^{1}$ and Viviane Rostirola Elsner ${ }^{*}$

${ }^{1}$ Postgraduate Program at Biosciences and Rehabilitation, Centro Universitário Metodista-IPA, Porto Alegre-RS, Brazil

${ }^{2}$ Postgraduate Program at Health Sciences, Universidade Federal de Ciências da Saúde de Porto Alegre UFCSPA), Brazil

${ }^{3}$ Postgraduate Program at Rehabilitation Sciences, Universidade Federal de Ciências da Saúde de Porto Alegre (UFCSPA), Brazil

\begin{abstract}
Objective: To verify the chronic consumption of grape juice effects on weight, body mass index (BMI), cognitive function and the peripheral levels of global histone $\mathrm{H} 4$ acetylation, BDNF and inflammatory markers in elderly women according to age. Methods: This is a quasi-experimental study. The blood samples were collected before and after 30 days of grape juice supplementation $(400 \mathrm{ml} /$ daily $)$ in women aged $>70$ and $<70$ years old. Weight, BMI and cognitive function, were measured before and after supplementation. Results: Grape juice consumption promoted a reduction on weight and BMI. This consumption also contributed to improve a cognitive function. These effects were more pronounced in the $>70$ years group. A tendency towards increased BDNF levels was observed in the $>70$ years group after intervention. Inflammatory markers and global histone $\mathrm{H} 4$ levels did not change. Conclusion: The chronic grape juice consumption is an interesting choice to promote health benefits in elderly women, which seem to act in an age-dependent manner.
\end{abstract}

\section{Introduction}

The current world scenario is characterized by a rapid and considerable increase in the elderly population [1]. This is critical information since the aging process is characterized by the progressive decline of physiological function that contributes to cognitive retardation and may increase the incidence of neurodegenerative diseases [2,3]. Thus, it is essential to elucidate the mechanisms involved during the aging process and investigate new approaches that can improve brain function. Recent evidences pointed out that both normal aging process and the physiopathology of neurodegenerative disease incidence and progression are linked to epigenetic pathways imbalance [4-6]. Epigenetic mechanisms modulate gene expression patterns without affecting the primary deoxyribonucleic acid (DNA) sequence in response to external factors and environmental cues such as diet and exercise $[4,7,8]$.

Histone acetylation is an important epigenetic marker linked to enhanced transcriptional activity $[9,10]$, catalyzed by histone acetyltransferases (HAT) [11]. Inversely, histone deacetylation, induced by histone deacetylases (HDAC) activity, is typically associated with transcriptional repression [12]. Interestingly, the HAT/HDAC imbalance appears to be pivotal in triggering the neurodegenerative cascade of events [6]. In this sense, increased levels of HDAC activity was detected in the hippocampi from aged rats [7]. Congruently, lower levels of global histone $\mathrm{H} 4$ acetylation in hippocampi from aged rats [7]. These findings could be related to the decreased levels and/ or expression of genes that exert pivotal role on memory and synaptic plasticity during the aging process, including the Brain Derived Neurotrophic Factor (BDNF) [13]. In fact, lower levels of peripheral BDNF are associated to the cognitive deficits in elderly people [14].

It is also reported that the aging process is accompanied by remodeling changes in the immune system which altered cytokine profile represents one of the most dramatic disturbances [15]. The imbalance between pro- and anti-inflammatory cytokines were observed, including an elevation of pro inflammatory cytokins such as tumoral necrosis factor alpha (TNF- $\alpha$ ), interleukin-6 (IL-6 and interferon-gamma (INF- $\gamma$ ) $[16,17]$. This status seems to be responsible for a chronic pro inflammatory profile, named inflammaging [18], recently described an interaction between the imbalance on immune system and cognitive deficits in humans. Furthermore, experimental data also reported that the aging-related memory decline is linked to histone $\mathrm{H} 4$ hypoacetylation levels and the modulation of inflammatory parameters [5].

Dietary components may be able to control cytokine deregulation in many diseases, in particular, natural bioactive compounds contribute to reduce the inflammation $[19,20]$. In this context, polyphenol compounds found in grape juice have been associated with multiple health benefits including improvement in cognition and neuronal function with aging [21-23]. Experimental studies conducted by our research group demonstrated the neuroprotective effects of chronic purple grape juice consumption in several brain areas from rats submitted to different damage models [24-26].

Correspondence to: Viviane Rostirola Elsner, Postgraduate Program in Biosciences and Rehabilitation of the Methodist University Center of IPA. Rua Coronel Joaquim Pedro Salgado, 80 - Rio Branco, Porto Alegre - RS, CEP 90420 060; Telephone / fax number: +55513316 1100; E-mail: vivielsner.fisiologia@gmail.com

Key words: grape juice supplementation, cognitive function, global Histone H4 acetylation levels, inflammatory markers, BDNF levels

Received: December 06, 2016; Accepted: December 29, 2016; Published: January 04, 2017 
However, the molecular mechanisms through which purple grape juice consumption improves cognitive outcomes during the aging process are not yet elucidated. Therefore, our aim was to evaluate the effect of chronic purple grape juice consumption according to the age on cognitive performance, peripheral levels of global histone $\mathrm{H} 4$ acetylation of BDNF, inflammatory profile and anthropometric parameters in healthy elderly women.

\section{Methods}

\section{Grape juice}

Grape juice used was the integral grape juice provided by Suvalan ${ }^{\circ}$ brand, packaged at $200 \mathrm{ml}$, all from the same batch (1771-13). Throughout the tests, we observed the expiration dates of the juice, phenolic compounds and chemical analysis. Table 1 shows the principal characteristics of the grape juice used. The content of total polyphenols was $53.6 \pm 0.18 \mathrm{mg}$ catechin $/ \mathrm{ml}$. The epicatechin and naringin appeared in higher concentrations. The physical and chemical parameters of the grape juice used attend to the Brazilian legislation.

\section{Subjects}

Sample size was set according to other studies performed in humans and with the aid of Winpepi program, considering 30\% coefficient of variation, $90 \%$ power and a 0.05 significance level [27-30].

The authors invited the elderly women through posters in hospitals and social networks. Women under sixty years old, carriers of neurodegenerative disease, diabetes (both types), and smokers were excluded from the study. Thirty-seven elderly women over sixty years old were interested in participating in the research, but there were two withdrawls and thirty-five completed the study $(\mathrm{n}=35)$. The desistance occurred in the first week of research. The first abandoned for experiencing accentuated epigastric pain and linked this to grape juice consumption; the second needed to undergo a surgery.

The volunteers were instructed to keep the same routine regarding diet, exercise, and medication during the thirty days of research to prevent possible confounders. During the intervention period, one month, the researchers each week certified that the volunteers consumed $400 \mathrm{ml} /$ day of grape juice. All the experimental procedure was performed at the same period.

\section{Experimental design}

This was a quasi-experimental study, aimed to evaluate interventions

Table 1. Grape Juice Characteristics.

\begin{tabular}{|c|c|c|}
\hline Analysis & Result & Method \\
\hline Total Phenolic Compound (mg catechin $/ \mathrm{mL}$ ) & $53.6 \pm 0.18$ & Ribèrau-Gayon, 2003 \\
\hline trans-Resveratrol $(\mathrm{mg} / \mathrm{L})$ & $0.79 \pm 0.01$ & MCMurtrey et al., 1994 \\
\hline Catechin $(\mathrm{mg} / \mathrm{L})$ & $1.03 \pm 0.03$ & HPLC \\
\hline Epicatechin (mg/L) & $5.38 \pm 0.06$ & HPLC \\
\hline Naringin $(\mathrm{mg} / \mathrm{L})$ & $6.96 \pm 0.21$ & HPLC \\
\hline Quercetin (mg/L) & $0.59 \pm 0.06$ & HPLC \\
\hline Total Acidity (g \% tartaricacid) & $0.54 \pm 0.00$ & IN n²4 08/09/2005 (In, 2005) \\
\hline Volatile acidity $(\mathrm{g} / 100 \mathrm{~g})$ & 0.00 & IN n²4 08/09/2005 (In, 2005) \\
\hline${ }^{\circ}$ Brix & $14.28 \pm 0.00$ & IN n²4 08/09/2005 (In, 2005) \\
\hline Relative density on $20^{\circ} \mathrm{C}$ & $1.058 \pm 0.00$ & IN n²4 08/09/2005 (In, 2005) \\
\hline Organoleptic Characteristics & Normal & IN n²4 08/09/2005 (In, 2005) \\
\hline $\mathrm{pH}$ & $3.33 \pm 0.01$ & IN n²4 08/09/2005 (In, 2005) \\
\hline Alcoholic grade $(\% \mathrm{v} / \mathrm{v})$ & 0.00 & IN n²4 08/09/2005 (In, 2005) \\
\hline Relation ${ }^{\circ}$ Brix/Total acidity (g \% tartaric acid) & $26.44 \pm 0.00$ & IN n²4 08/09/2005 (In, 2005) \\
\hline
\end{tabular}

but that do not use randomization. Similar to randomized trials, quasiexperiments aim to demonstrate causality between an intervention and an outcome [31,32]. Considering the difficulty of obtaining a placebo group or a control group (without any grape derivate consumption) we justify our choice in doing a quasi-experimental design without control groups. This difficulty could be explained because our state is one of the most important regions in grape cultivation, and for this reason we have a high consumption of these products.

The survey was conducted in three meetings. At the first one the search mechanism and the criteria for blood collection were explained; the other two meetings were divided into before and after supplementation, following according to Figure 1. In these two meetings, anthropometric measurements were collected and Mini Mental State Examination (MMSE) was applied to evaluate the cognitive performance. Blood samples $(10 \mathrm{ml})$ were collected for the measurement of global histone $\mathrm{H} 4$ and BDNF levels as well inflammatory parameters.

The volunteers received all the required amount of juice for the thirty days of research in the before meeting, consuming $400 \mathrm{ml}$ daily. E-mails, text messages, and phone calls were made in order to remind volunteers about the consumption requirements.

\section{Evaluation of anthropometric parameters}

These parameters were analyzed before and after supplementation. Semi-analytical Balance Welmy with coupled stadiometer (Santa Barbara D’Oeste, São Paulo, Brazil) was used to evaluate the height $(\mathrm{m})$ and weight $(\mathrm{kg})$. Waist circumference $(\mathrm{cm})$ and hip circumference $(\mathrm{cm})$ were measured with a flexible tape. Body mass index $(\mathrm{BMI}=\mathrm{kg} /$ $\mathrm{m}^{2}$ ) was obtained using the formula weight/height ${ }^{2}$. The investigators responsible for these measures were the same, before and after the intervention.

\section{Cognitive performance assessment}

Cognitive performance was measured using the Portuguese version of the Mini Mental State Examination (MMSE) [33]. The test provides a brief evaluation of the cognitive domains including orientation, registration, attention, recall, language, and constructional praxis. Patients' scores range from 0 to 30 , with low scores indicating greater cognitive impairment. Cutoffs were used to grade severity of change as mild, moderate, or severe. Namely, mild cognitive impairment was considered when the patient was rated $20-24$ points, moderate cognitive impairment with 16-19 points, and severe cognitive impairment with 


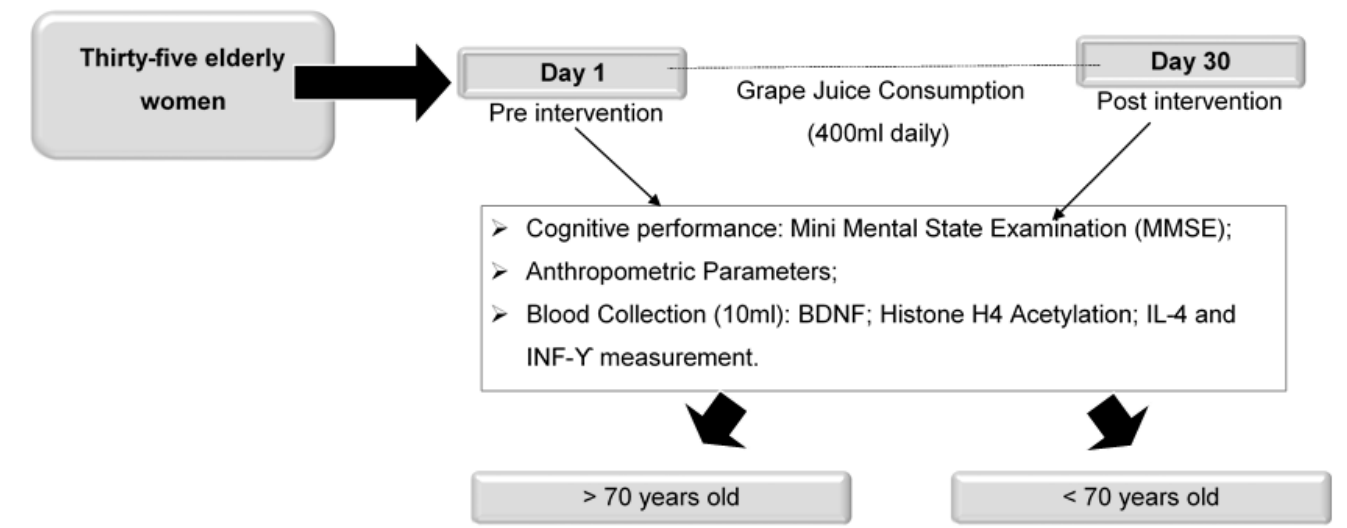

Figure 1. Flowchart of experimental design in the initial and final meetings. Only in the initial meeting. MMSE - Mini Mental State Examination.

15 or fewer points. The cutoff score for dementia is 19 points. The test sensitivity was $87 \%$, and specificity was $82 \%$.

\section{Extraction of peripheral blood mononuclear cells (PBMC)}

PBMC were extracted by Ficol gradient. Histopaque ${ }^{\circledast}$ (SigmaAldrich 1077) was added in the collected sample in a 1:1 proportion in a conical tube and then centrifugation was held at $1500 \mathrm{rpm}$ for 30 minutes at room temperature. After that, the "buffer coat" was removed

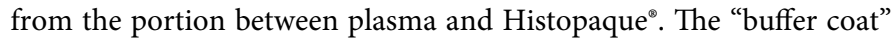
was washed 5 times with phosphate buffered saline solution (PBS $\mathrm{pH}$ 7.4) and then centrifugation was held at $1800 \mathrm{rpm}$ for 10 minutes at room temperature. The formed pellet was collected and used for evaluation of acetylation levels of histone $\mathrm{H} 4$. Cell viability was always higher than $95 \%$. The remaining plasma was collected and stored in conical tubes $(1.5 \mathrm{ml})$ at $-80^{\circ} \mathrm{C}$ for later determination of BDNF levels.

\section{Determination of BDNF levels}

BDNF levels were determined with the enzyme-linked immunosorbent assay (ELISA) method, from Sigma-Aldrich commercial kit (catalog number RAB0026) according to manufacturer's instructions. To perform the test the remaining plasma samples from the leukocyte extract were used. These, together with BDNF specific standards, were added to ELISA microplate and incubated for 2.5 hours at room temperature.

Subsequently, the solutions were discarded and the same plate was washed 4 times with wash buffer (PBS, Tween 20 0.01\%). After washing, the secondary antibody bound to biotin was added and incubated for 1 hour at room temperature with gentle agitation. The plate was again washed with wash buffer and streptavidin solution was added. The plate was incubated at room temperature for 45 minutes with gentle agitation. The solution was discarded and the plate passed through the washing process. Tetramethylbenzidine (TMB) was added, and incubated for 30 minutes at room temperature under light deprivation with gentle agitation. The stop solution was added and the plate was read in a spectrophotometer at a wavelength of $450 \mathrm{~nm}$.

\section{Determination of global histone $\mathrm{H} 4$ acetylation levels}

The global histone H4 acetylation levels were determined using the Global Histone H4 Acetylation Assay Kit (Colorimetric Detection, catalog number P-4009, EpiQuik USA) according to the manufacturer's instructions. The extracted leukocyte cells from the blood samples were processed with a specific nuclear extract lysis-buffer followed by histone extraction. The extraction was carried out with trichloroacetic acid, chloridric acid and acetone; the formed pellet was used for the $\mathrm{H} 4$ acetylation detection. The samples were incubated with the capture antibody followed by incubation with detection antibody. After, the samples were incubated with developing solution followed by the addition of the Stop Solution. The absorbance was measured on a spectrophotometer at a wavelength of $450 \mathrm{~nm}$. The global histone $\mathrm{H} 4$ acetylation levels were expressed as ng/mg protein. Protein content was performed using the Biuret method. For this, we used the commercial kit of Total Protein (Labtest Diagnostics S/A, Lagoa Santa, MG, Brazil), following the manufacturer's methodology.

\section{Determination of cytokine levels}

The systemic levels of INF-y and IL-4 were determined by ELISA with specific kits (Mini ELISA Development Kit, 900-M21, PeproTech Inc., NJ) and following the manufacturer's recommendations. To avoid errors due to intra-assay sensitivity, all cytokine's analyses were performed on the same plate on the same day. Plates of 96 wells were incubated overnight with capture antibody, anti-INF-y or IL-4 diluted in 1PBS buffer. After blocking for $1 \mathrm{~h}$ to avoid nonspecific binding, $100 \mathrm{ml}$ of standard INF-y or IL-4 and serum samples were placed. The cytokines were detected by horseradish peroxidase-labeled monoclonal antibody to each target after the addition of $100 \mu \mathrm{l}$ antihuman INF-y or IL-4 biotinylated antibodies, they were placed in each well and incubated for $2 \mathrm{~h}$ at room temperature. The microplate was washed to remove unbound enzyme-labeled antibodies. The amount of horseradish peroxidase bound to each well was determined by the addition of $100 \mathrm{ml}$ substrate solution. The reaction was stopped by the addition of $100 \mathrm{ml}$ of $1 \mathrm{M}$ sulfuric acid, and the plates read at $450 \mathrm{~nm}$ (ThermoPlate, São Paulo, Brazil). The concentrations of cytokines were determined by interpolation from standard curve and presented as $\mathrm{pg} / \mathrm{ml}$.

\section{Ethical procedures}

All participants read and signed the Informed Consent (IC), according to Resolution $466 / 12$ of the Brazilian National Health Council. The Research Ethics Committee of the Centro Universitário Metodista - IPA approved the study under protocol 1.174.858.

\section{Statistical analysis}

Data were checked for normality by Shapiro-Wilk test. Parametric data presented as mean \pm standard deviation and compared pre-post supplementation through paired t-test. For the variables that deviated from normality, we used the nonparametric Wilcoxon test (median and interquartile range). Comparison between groups was performed 
unpaired Student t-test (for parametric variables) or Mann-Whitney $\mathrm{U}$ test (nonparametric variables). Correlations performed through Spearman test. All analyses were performed by SPSS 20.0 (IBM., NY, USA). All statistical tests were two-tailed and were performed using a significance level of $\mathrm{p}<0.05$.

\section{Results}

Thirty five elderly women participated in the present study, 16 of them were in the $<70$ years old group and 19 were in the $>70$ years old group (Table 2).

Firstly, we evaluated the effect of chronic grape juice consumption on cognitive performance, anthropometric and biochemical parameters. Table 2 shows a significant reduction on body mass and BMI as well improved the cognitive performance $(\mathrm{p}=0.001)$ after supplementation in both groups ( $>70$ and $<70$ years old).

When the sample was separated in $>70$ and $<70$ years old groups, it was observed a clear impact of age in these responses, as highlighted in Table 3. Specifically, the grape juice consumption did not alter body mass and BMI in the $<70$ years women, while diminished significantly both parameters in the oldest group. Regarding the cognitive performance, the improvement after the grape juice consumption appears in the $<70$ and $>70$ years old groups. Interestingly, $\Delta$ value in the $>70$ group was higher when compared to $<70$ women ( $\mathrm{p}=0.04)$, as demonstrated in Figure 2. Finally, the $>70$ group showed a tendency towards increased BDNF levels $(\mathrm{p}=0.069)$ after the supplementation (Table 3).

However, neither age nor grape juice supplementation altered significantly the systemic cytokine and global histone H4 levels $(\mathrm{p}>0.05$; Table 3).

\section{Discussion}

In the current study, we provide the first evidence reporting the beneficial effects of grape juice consumption on antropometric parameters and cognitive performance in elderly women. A novel and important finding that emerged from our study is that response and seem to vary in an age-dependent manner.

The improvement on cognition after supplementation was evaluated through the MMSE. This is a validated and effective instrument that asses five domains of cognition in elderly taken as orientation with regard to time and place, registration of words, attention and calculation, recall, and language $[33,34]$.

In agreement to our findings, other studies conducted with elderly people also showed that the consumption of beverages rich in polyphenol such as blueberry juice improved the cognitive abilities [21]. The beneficial effect of grape juice on brain function was also highlighted in experimental models. Some authors demonstrated that treatment with grape polyphenol preparation prevented peripheral metabolic abnormality as well improved brain synaptic plasticity in a mouse, which is pivotal for the learning and the memory process [35]. In addition, other study with animal model for Alzheimer's disease suggests that grape juice consumption for 21 days is able to improve the learning and memory functions evaluated through the passive avoidance learning test [36]. Taken together, these findings support the idea that chronic purple grape juice consumption is a potential tool able

Table 2. Pre-post Comparison.

\begin{tabular}{|c|c|c|c|c|}
\hline & Pre supplementation & After supplementation & $\Delta \%$ & $\mathbf{p}$ \\
\hline Age (years) & $69.49 \pm 6.97$ & - & - & - \\
\hline Body mass (kg) & $66.00(16,325)$ & $65.11(17,775)$ & $-0.37 \pm 0.89$ & 0.011 \\
\hline $\operatorname{BMI}\left(\mathrm{kg} / \mathrm{m}^{2}\right)$ & $26.354(6.42)$ & $26.298(5.977)$ & $-0.11 \pm 0.40$ & 0.03 \\
\hline $\mathrm{INF}-\gamma(\mathrm{pg} / \mathrm{mL})$ & $6.23 \pm 1.43$ & $6.26 \pm 1.02$ & $0.11 \pm 1.35$ & 0.69 \\
\hline $\mathrm{IL}-4(\mathrm{pg} / \mathrm{mL})$ & $4.09 \pm 1.67$ & $4.58 \pm 1.45$ & $0.24 \pm 1.46$ & 0.66 \\
\hline Ratio IL-4/INF- $\gamma$ & $1.80 \pm 0.98$ & $1.49 \pm 0.51$ & $-0.17 \pm 1.07$ & 0.45 \\
\hline $\mathrm{BDNF}(\mathrm{pg} / \mathrm{mL})$ & $721.37(310.88)$ & $808.26(308.09)$ & $304.71 \pm 932.48$ & 0.12 \\
\hline Histone $\mathrm{H} 4$ acetylation levels ( $\mathrm{ng} / \mathrm{mg}$ of protein) & $756.22(498.40)$ & $564.73(477.54)$ & $62.19 \pm 3107.90$ & 0.35 \\
\hline
\end{tabular}

Data presented as mean $\pm \mathrm{SD}$ (parametric values) or median with interquartile range (nonparametric values).Pre-after comparison through paired Student t-test or Wilcoxon test. BMI, Body mass index; INF- $\gamma$, Interferon-gamma; IL-4, interleukin-4; BDNF, Brain-derived neurotrophic factor.

Table 3. Pre-post comparison with age.

\begin{tabular}{|c|c|c|c|c|c|c|}
\hline & & Pre & After & $\mathrm{P}$ & $\Delta \%$ & $\mathrm{p} \neq$ \\
\hline \multirow[t]{2}{*}{ Body Mass (Kg) } & $<70$ & $66.92 \pm 12.71$ & $66.66 \pm 12.56$ & 0.254 & $-0.30 \pm 0.77$ & 0.912 \\
\hline & $>70$ & $66.40(15.99)$ & $65.60(17.325)$ & 0.015 & $-0.35 \pm 1.01$ & \\
\hline \multirow[t]{2}{*}{ BMI (Kg/m2) } & $<70$ & $27.69 \pm 5.971$ & $27.62 \pm 5.909$ & 0.553 & $-0.13 \pm 0.35$ & 0.816 \\
\hline & $>70$ & $26.35(6.154)$ & $25.712(6.139)$ & 0.035 & $-0.09 \pm 0.45$ & \\
\hline \multirow[t]{2}{*}{ INF-Y (pg/mL) } & $<70$ & $6.13 \pm 1.43$ & $6.01 \pm 1.53$ & 0.164 & $-0.35 \pm 0.77$ & 0.117 \\
\hline & $>70$ & $5.61 \pm 1.5$ & $6.16 \pm 0.94$ & 0.280 & $0.54 \pm 1.64$ & \\
\hline \multirow[t]{2}{*}{ IL-4 (pg/mL) } & $<70$ & $4.06 \pm 1.47$ & $4.14 \pm 1.43$ & 0.860 & $0.27 \pm 1.54$ & 0.928 \\
\hline & $>70$ & $4.26 \pm 1.54$ & $4.30 \pm 1.56$ & 0.667 & $0.21 \pm 1.46$ & \\
\hline \multirow[t]{2}{*}{ Ratio IL-4/INF- $\Upsilon$} & $<70$ & $1.72(0.94)$ & $1.41(0.95)$ & 0.286 & $-0.07(1.69)$ & 0.519 \\
\hline & $>70$ & $1.18(0.8)$ & $1.25(0.42)$ & 0.859 & $0.02(0.93)$ & \\
\hline \multirow[t]{2}{*}{ BDNFlevels (pg/ml) } & $<70$ & $817.23(459.46)$ & $883.42(300.81)$ & 0.717 & $119.7(703.52)$ & 0.196 \\
\hline & $>70$ & $600.26(275.26)$ & $741.63(446.51)$ & 0.069 & $215.40(412.29)$ & \\
\hline \multirow{2}{*}{$\begin{array}{l}\text { Histone H4 Acetylation levels } \\
\text { (ng/mg of protein) }\end{array}$} & $<70$ & $634.12(849.92)$ & $709.52(716.36)$ & 0.438 & $-166.78(438.18)$ & 0.297 \\
\hline & $>70$ & $816.90(482.2)$ & $469.41(386.43)$ & 0.586 & $-346.26(1006.08)$ & \\
\hline
\end{tabular}

Data presented as mean $\pm \mathrm{SD}$ (parametric values) or median with interquartile range (nonparametric values). Pre-after comparison through paired Student t-test or Wilcoxon test. $\mathrm{p} \neq$ Intergroup comparison by Unpaired Student t-test or Mann Whitney U-Test. BMI, Body mass index; INF- $\gamma$, Interferon-gamma; IL-4, interleukin-4; BDNF, Brain-derived neurotrophic factor. 


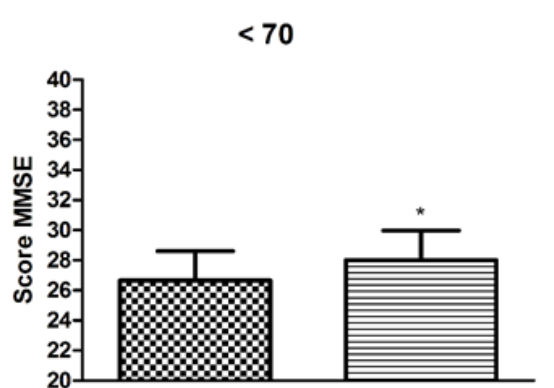

(a)
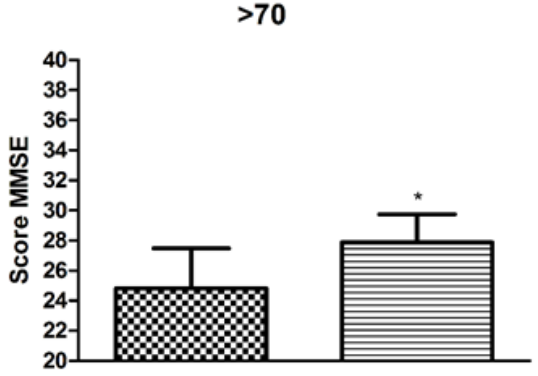

(b)

Figure 2.The effect of chronic grape juice consumption on MMSE test. (a) age group under seventy years old. (b) age group above seventy years old. Data presented as mean $\pm \mathrm{SD}$ (parametric values). Before and after comparison through paired Student t-test. * Statistic difference after supplementation $(\mathrm{p}<0.005)$.

to improve cognitive performance not only during the physiological age process as well in neurodegenerative conditions [37].

A remarkable point to discuss is that the cognitive performance improvement seem to be more evident in the aged women, since the $>70$ group showed a greater difference in MMSE scores compared to the $<70$ women after the supplementation. This data might be related to the increased tendency on BDNF levels in the $>70$ group since this neurotrophin exert an important role in both learning and memory abilities [38].

Emerging evidences have shown that being overweight is negatively associated with cognitive functions, whereas weight loss may improve it in middle-aged and elderly people [39-41]. In support of this view, a recent study showed that diet modification promoted weight loss in overweight postmenopausal women and increased hippocampal activity during memory encoding. The authors also state that weight loss may decrease risk of developing dementia [42]. Corroborating this idea, another study demonstrated that long-term consumption of a high-calorie diet could inhibit autophagy function and facilitate neuronal loss in the hippocampus, which in turn aggravate age related cognition impairment [43]. In accordance, besides the improvement of cognitive function, the present study also found a significant reduction on body mass and BMI after grape juice consumption in all individuals. Besides, these changes were more significant in the $>70$ years old women.

Consistent with these considerations, we postulate that the enhancement on cognitive ability following grape juice supplementation in elderly women is related, at least in part, to the body mass reduction. It is also plausible to suppose that the positive effects of this intervention are more pronounced with advancing age.
Although substantial evidences have been supporting the pivotal role of epigenetic regulation on polyphenol compounds mechanisms of action [44-46], the chronic grape juice consumption was not able to do it. Importantly, the cited studies are focused in the context of the polyphenol diet use on the management and therapeutic targets of age-related diseases, differently from our sample, consisted of healthy elderly women. Then, we might hypothesize that polyphenol compounds could act as the source of epigenetic modifications preferentially in pathological condition during the aging process.

Finally, it is important to consider that the intervention used in our study was chronic. On the other hand, experimental and clinical studies already reported that the impact of external stimuli such as exercise on acetylation levels status could be dynamic and with short-lived and acute outcomes, without any delayed effect $[4,47,48]$. This response may be act as a protective mechanism to maintain the homeostasis of the transcriptional machinery. Further studies should investigate the acute effect of grape juice consumption to elucidate this question.

\section{Conclusion}

Summarizing, our data indicate that chronic grape juice consumption is able to contribute in cognitive performance ameliorate in elderly women, which seems to be related, at least in part, to BMI and body mass reduction. This beneficial response might vary through lifespan, been more evident in the oldest group, and did not engage the modulation of inflammatory and epigenetic signals. This pioneer study opens new avenues for further investigations in order to elucidate the molecular mechanism involved behind this phenomenon.

\section{Acknowledgements}

This work was supported by IBRAVIN, Coordenação de Aperfeiçoamento de Pessoal de Nível Superior (CAPES)/Brazil and Fundação de Amparo à Pesquisa do Estado do Rio Grande do Sul (FAPERGS)/Brazil.

\section{Declaration of conflicting interests}

The Authors declare that there is no conflict of interest.

\section{References}

1. Park DC, Reuter-Lorenz P (2009) The adaptive brain: aging and neurocognitive scaffolding. Annual Review of Psychology 60: 173-196. [Crossref]

2. Buckner RL (2004) Memory and executive function in aging and AD: multiple factors that cause decline and reserve factors that compensate. Neuron 44: 195-208. [Crossref]

3. Henderson VW (2014) Three midlife strategies to prevent cognitive impairment due to Alzheimer's disease. Climacteric 2: 38-46. [Crossref]

4. Elsner VR, Lovatel GA, Bertoldi K, Vanzella C, Santos FM, et al. (2011) Effect of different exercise protocols on histone acetyltransferases and histone deacetylases activities in rat hippocampus. Neuroscience 192: 580-587. [Crossref]

5. Lovatel GA, Bertoldi K, Elsnerb VR, Piazza FV, Basso CG, et al. (2014) Long-term effects of pre and post-ischemic exercise following global cerebral ischemia on astrocyte and microglia functions in hippocampus from Wistar rats. Brain Research 1587: 119-126. [Crossref]

6. Saha RN, Pahan K (2006) HATs and HDACs in neurodegeneration: a tale of disconcerted acetylation homeostasis. Cell Death Differ 13: 539-550. [Crossref]

7. Dos Santos Sant' Anna G, Rostirola Elsner V, Moyses F, Reck Cechinel L, Agustini Lovatel G, et al. (2013) Histone deacetylase activity is altered in brain areas from aged rats. Neuroscience Letters 556: 152-154. [Crossref]

8. Milenkovic D, Vanden Berghe W, Boby C, Leroux C, Declerck K, et al. (2014) Dietary flavanols modulate the transcription of genes associated with cardiovascular pathology without changes in their DNA methylation state. PloS One 9: e95527. [Crossref]

9. Choi JK, Howe LJ (2009) Histone acetylation: truth of consequences? Biochem Cell 


\section{Biol 87: 139-150. [Crossref]}

10. Kimura A, Matsubara K, Horikoshi M (2005) A decade of histone acetylation: marking eukaryotic chromosomes with specific codes. Journal of Biochemistry 138: 647-662. [Crossref]

11. Strahl BD, Allis CD (2000) The language of covalent histone modifications. Nature 403: 41-45. [Crossref]

12. Kouzarides T (2007) Chromatin modifications and their function. Cell 128: 693-705. [Crossref]

13. Kohman RA, Rodriguez-Zas SL, Southey BR, Kelley KW, Dantzer R, et al. (2011) Voluntary wheel running reverses age-induced changes in hippocampal gene expression. PLoS One 6: e22654. [Crossref]

14. Yu H, Zhang Z, Shi Y, Bai F, Xie C, et al. (2008) Association study of the decreased serum BDNF concentrations in amnestic mild cognitive impairment and the Val66Met polymorphism in Chinese Han. The Journal of clinical psychiatry 69: 1104-1111. [Crossref]

15. Wakikawa A, Utsuyama M, Wakabayashi A, Kitagawa M, Hirokawa K (1999) Vitamin E enhances the immune functions of young but not old mice under restraint stress. Exp Gerontol 34: 853-862. [Crossref]

16. Fernandez-Gutierrez B, Zamorano J, Batlle E, Alfonso F, Conde A, et al. (1999) Coronary dissection associated with hepatitis $\mathrm{C}$ virus-related cryoglobulinaemia. Rheumatology 38: 1299-1301. [Crossref]

17. Neuber K, Schmidt S, Mensch A (2003) Telomere length measurement and determination of immunosenescence-related markers (CD28, CD45RO, CD45RA, interferon-gamma and interleukin-4) in skin-homing T cells expressing the cutaneous lymphocyte antigen: indication of a non-ageing T-cell subset. Immunology 109: 24-31. [Crossref]

18. Deleidi M, Jäggle M, Rubino G (2015) Immune aging, dysmetabolism, and inflammation in neurological diseases. Front Neurosci 9: 172. [Crossref]

19. Minihane AM, Vinoy S, Russell WR, Baka A, Roche HM, et al. (2015) Low-grade inflammation, diet composition and health: current research evidence and its translation. The British Journal of Nutrition 114: 999-1012. [Crossref]

20. Panickar KS, Jewell DE (2015) The beneficial role of anti-inflammatory dietary ingredients in attenuating markers of chronic low-grade inflammation in aging. Hormone Molecular Biology and Clinical Investigation 23: 59-70. [Crossref]

21. Krikorian R, Boespflug EL, Fleck DE, Stein AL, Wightman JD, et al. (2012) Concord grape juice supplementation and neurocognitive function in human aging. Journal of Agricultural and Food Chemistry 60: 5736-5742. [Crossref]

22. Letenneur L, Proust-Lima C, Le Gouge A, Dartigues JF, Barberger-Gateau P (2007) Flavonoid intake and cognitive decline over a 10-year period. Am J Epidemiol 165: 1364-1371. [Crossref]

23. Nurk E, Refsum H, Drevon CA, Tell GS, Nygaard HA, et al. (2009) Intake of flavonoid-rich wine, tea, and chocolate by elderly men and women is associated with better cognitive test performance. J Nutr 139: 120-127. [Crossref]

24. Cardozo MG, Medeiros N, Lacerda Ddos S, de Almeida DC, Henriques JA, et al. (2013) Effect of chronic treatment with conventional and organic purple grape juices (Vitis labrusca) on rats fed with high-fat diet. Cellular and Molecular Neurobiology 33: 1123-1133. [Crossref]

25. Dani C, Oliboni LS, Umezu FM, Pasquali MA, Salvador M, et al. (2009) Antioxidant and antigenotoxic activities of purple grape juice--organic and conventional--in adult rats. Journal of Medicinal Food 12: 1111-1118. [Crossref]

26. Gabardo T, Peripolli CM, de Andrade RB, Gemelli T, Lima JDO, et al. (2015) Assessment of changes in energy metabolism parameters provoked by carbon tetrachloride in Wistar rats and the protective effect of white grape juice. Toxicology Reports 2: 645-653. [Crossref]

27. Castilla P, Echarri R, Dávalos A, Cerrato F, Ortega H, et al. (2006) Concentrated red grape juice exerts antioxidant, hypolipidemic, and antiinflammatory effects in both hemodialysis patients and healthy subjects. Am J Clin Nutr 84. [Crossref]

28. Khadem-Ansari MH, Rasmi Y, Ramezani F (2010) Effects of red grape juice consumption on high density lipoprotein-cholesterol, apolipoprotein AI, apolipoprotein $\mathrm{B}$ and homocysteine in healthy human volunteers. The Open Biochemistry Journal 4: 96-99. [Crossref]

29. Park YK, Park E, Kim JS, Kang MH (2003) Daily grape juice consumption reduces oxidative DNA damage and plasma free radical levels in healthy Koreans. Mutation Research 529: 77-86. [Crossref]
30. Zibaeenezhad MJ, Mohammadi E, Babaie Beigi MA, Mirzamohammadi F, Salehi O (2012) The effects of unripe grape juice on lipid profile improvement. Cholesterol 2012 890262. [Crossref]

31. Shadish WR (2002) Revisiting field experimentation: field notes for the future. Psychol Methods 7: 3-18. [Crossref]

32. Trochim W, Donnelly JP (2006) The Research Methods Knowledge Base: Cengage Learning.

33. Folstein MF, Folstein SE, McHugh PR (1975) "Mini-mental state". A practical method for grading the cognitive state of patients for the clinician. Journal of Psychiatric Research 12: 189-198. [Crossref]

34. Tombaugh TN, McIntyre NJ (1992) The mini-mental state examination: comprehensive review. Journal of the American Geriatrics Society 40: 922-935. [Crossref]

35. Wang J, Tang C, Ferruzzi MG, Gong B, Song BJ, et al. (2013) Role of standardized grape polyphenol preparation as a novel treatment to improve synaptic plasticity through attenuation of features of metabolic syndrome in a mouse model. Molecular Nutrition \& Food Research 57: 2091-2102. [Crossref]

36. Siahmard Z, Alaei H, Reisi P, Pilehvarian AA (2012) The effect of red grape juice on Alzheimer's disease in rats. Adv Biomed Res 1: 63. [Crossref]

37. Day AP, Kemp HJ, Bolton C, Hartog M, Stansbie D (1997) Effect of concentrated red grape juice consumption on serum antioxidant capacity and low-density lipoprotein oxidation. Annals of Nutrition \& Metabolism 41: 353-357. [Crossref]

38. Binder DK, Scharfman HE (2004) Brain-derived neurotrophic factor. Growth Factors 22: 123-131. [Crossref]

39. Siervo M, Arnold R, Wells JC, Tagliabue A, Colantuoni A, et al. (2011) Intentional weight loss in overweight and obese individuals and cognitive function: a systematic review and meta-analysis. Obesity Reviews 12: 968-983. [Crossref]

40. Witte AV, Fobker M, Gellner R, Knecht S, Floel A (2009) Caloric restriction improves memory in elderly humans. Proceedings of the National Academy of Sciences of the United States of America 106: 1255-1260. [Crossref]

41. Witte AV, Kerti L, Margulies DS, Floel A (2014) Effects of resveratrol on memory performance, hippocampal functional connectivity, and glucose metabolism in healthy older adults. Journal of the Society for Neuroscience 34: 7862-7870. [Crossref]

42. Boraxbekk CJ, Stomby A, Ryberg M, Lindahl B, Larsson C, et al. (2015) Diet-Induced Weight Loss Alters Functional Brain Responses during an Episodic Memory Task. Obesity Facts 8: 261-272. [Crossref]

43. Dong W, Wang R, Ma LN, Xu BL, Zhang JS, et al. (2016) Influence of age-related learning and memory capacity of mice: different effects of a high and low caloric diet. Aging Clinical and Experimental Research 28: 303-311. [Crossref]

44. Barrajon-Catalan E, Herranz-Lopez M, Joven J, Segura-Carretero A, Alonso-Villaverde C, et al. (2014) Molecular promiscuity of plant polyphenols in the management of age-related diseases: far beyond their antioxidant properties. Advances in Experimental Medicine and Biology 824: 141-159. [Crossref]

45. Park LK, Friso S, Choi SW (2012) Nutritional influences on epigenetics and age-related disease. Proc Nutr Soc 71: 75-83. [Crossref]

46. Verma S, Singh A, Mishra A (2013) Molecular Dynamics Investigation on the Inhibition of MDM2-p53 Interaction by Polyphenols. Molecular Informatics 32: 203 212. [Crossref]

47. Chandramohan Y, Droste SK, Arthur JS, Reul JM (2008) The forced swimminginduced behavioural immobility response involves histone $\mathrm{H} 3$ phospho-acetylation and c-Fos induction in dentate gyrus granule neurons via activation of the N-methylD-aspartate/extracellular signal-regulated kinase/mitogen- and stress-activated kinase signalling pathway. The European Journal of Neuroscience 27: 2701-2713. [Crossref]

48. McGee SL, Fairlie E, Garnham AP, Hargreaves M (2009) Exercise-induced histone modifications in human skeletal muscle. J Physiol 587: 5951-5958. [Crossref]

Copyright: (C2017 Costa PC. This is an open-access article distributed under the terms of the Creative Commons Attribution License, which permits unrestricted use, distribution, and reproduction in any medium, provided the original author and source are credited. 